\title{
The antiapoptotic gene survivin is highly expressed in human chondrosarcoma and promotes drug resistance in chondrosarcoma cells in vitro
}

\author{
Philipp Lechler ${ }^{1 *}$, Tobias Renkawitz ${ }^{1}$, Valentina Campean², Sanjeevi Balakrishnan ${ }^{3}$, Markus Tingart ${ }^{4}$, \\ Joachim Grifka ${ }^{1}$ and Jens Schaumburger ${ }^{1}$
}

\begin{abstract}
Background: Chondrosarcoma is virtually resistant to chemotherapy and radiation therapy. Survivin, the smallest member of the inhibitor of apoptosis protein family, is a critical factor for tumor progression and resistance to conventional therapeutic approaches in a wide range of malignancies. However, the role of survivin in chondrosarcoma has not been well studied. We examined the importance of survivin gene expression in chondrosarcoma and analysed its influences on proliferation, apoptosis and resistance to chemotherapy in vitro.
\end{abstract}

Methods: Resected chondrosarcoma specimens from which paraffin-embedded tissues could be extracted were available from 12 patients. In vitro experiments were performed in human chondrosarcoma cell lines SW1353 and Hs819.T. Immunohistochemistry, immunoblot, quantitative PCR, RNA interference, gene-overexpression and analyses of cell proliferation and apoptosis were performed.

Results: Expression of survivin protein was detected in all chondrosarcoma specimens analyzed, while undetectable in adult human cartilage. RNA interference targeting survivin resulted in a $\mathrm{G}_{2} / \mathrm{M}$-arrest of the cell cycle and led to increased rates of apoptosis in chondrosarcoma cells in vitro. Overexpression of survivin resulted in pronounced resistance to doxorubicin treatment.

Conclusions: These findings indicate that survivin plays a role in the pathogenesis and pronounced chemoresistance of high grade chondrosarcoma. Survivin antagonizing therapeutic strategies may lead to new treatment options in unresectable and metastasized chondrosarcoma.

\section{Background}

Chondrosarcomas comprise a heterogeneous group of neoplasms characterized by the production of cartilage matrix by malignant cells [1] and represent the third most common primary malignancy of bone after myeloma and osteosarcoma [2]. Curative treatment of chondrosarcoma is restricted to surgical resection because of pronounced resistance to chemotherapy and radiation therapy [3-5]. The histological grade is directly related to metastatic rate and remains currently the single

\footnotetext{
* Correspondence: p.lechler@asklepios.com

'Department of Orthopedic Surgery, Regensburg University Medical Center,

Asklepios Klinikum Bad Abbach, Bad Abbach, Germany

Full list of author information is available at the end of the article
}

relevant predictor of patient outcome [6,7]. After adequate resection, 10-year survival for patients with grade I chondrosarcoma is excellent, whereas only $64 \%$ for grade II and $29 \%$ for grade III tumors [8]. A large body of evidence has demonstrated that chondrosarcoma's malignant phenotype and resistance to drug therapy is favoured by constitutive activation of antiapoptotic pathways and loss of cell cycle control $[9,10]$.

Survivin, the smallest member of the inhibitor of apoptosis protein (IAP) family is reported to fulfil important roles in cancer initiation, tumor progression and drug/radiation resistance [11]. The molecular structure of survivin reveals one $\mathrm{N}$-terminal baculovirus IAP repeat (BIR) domain and a long $\mathrm{C}$-terminal helix-coiled

\section{Biomed Central}


region. In solution, survivin forms stable homodimers $[12,13]$. Extensive alternative splicing and a finely, by transcriptional and post-transcriptional mechanisms, controlled expression regulate survivin [14]. It is a bifunctional protein that acts as a suppressor of cell death and plays a key role in cell division. As a chromosomal passenger protein survivin accumulates to kinetochores at metaphase, localizes to the spindle mid-zone at anaphase and is expressed in mid-bodies at telophase $[15,16]$. While survivin is highly expressed in cancer and during embryonal development it is said to be absent in most adult differentiated organs. Thus, survivin appears to be an ideal therapeutic target for cancer treatment with little toxicity to normal tissues [17]. However, little knowledge exists about expression of survivin in chondrosarcoma [18]. Here, we demonstrate, that the antiapoptotic protein survivin is highly expressed in human high grade chondrosarcoma and possibly acting as a major factor for the tumor's pronounced drug resistance.

\section{Methods}

Unless otherwise stated all chemicals were purchased from Sigma-Aldrich (Taufkirchen, Germany).

The study was approved by the Local Ethics Committee from the University of Regensburg ( ${ }^{\circ} 09-131$ and $\mathrm{N}^{\circ}$ 10-101-0170).

\section{Collection of human tissues}

Human chondrosarcoma tissues were collected from radical tumorextirpation, either fixed in $4 \%$ para-formaldehyde (immunohistochemistry) or snap frozen (immunoblot). Tumor specimens were analyzed by 2 independent pathologists. Histopathologic diagnosis and tumor grade were confirmed by a national reference pathologist. Detailed patient information can be found on table 1.
Non-arthritic human cartilage of 6 Patients undergoing total knee replacement because of mono- or bicompartmental osteoarthritis was collected. The macroscopically and microscopically healthy chondral layer of the unaffected compartment was harvested and either snap frozen or fixed in $4 \%$ paraformaldehyde. The mean donor age was 43 years ( 34 to 56 years). Written informed consent was obtained from each patient.

\section{Survivin immunohistochemistry}

Survivin immunohistochemistry was performed as previously reported [19]. In short, paraffin-embedded specimens were cut into $4 \mu \mathrm{m}$ sections, dewaxed, and rehydrated in ethanol. Endogenous peroxidase activity was blocked by incubation with $10 \% \mathrm{H}_{2} \mathrm{O}_{2}$ /phosphatebuffered saline at room temperature. Immunohistochemical staining was performed according to a commercial protocol based on a streptavidin-biotinperoxidase reaction (DAKO, Hamburg, Germany). For antigen retrieval, sections were cooked for 20 minutes in citrate buffer ( $\mathrm{pH}$ 6.0) by using a standardized pressure cooker (Biocare Medical, Walnut Creek, CA). Unspecific signals were blocked by incubation with $5 \%$ fat-free milk/phosphate-buffered saline for 1 hour at room temperature. Next, sections were incubated with primary antibodies overnight at $4{ }^{\circ} \mathrm{C}$. Thorough washing with tris-buffered saline $(50 \mathrm{mmol} / \mathrm{L}$ Tris- $\mathrm{HCl}$ and 136 $\mathrm{mmol} / \mathrm{L} \mathrm{NaCl}, \mathrm{pH}$ 7.4) was followed by incubation with biotinylated secondary antibody for 20 minutes. Subsequent to this the slides were incubated with avidinhorseradish peroxidase and the DAB substrate. All incubations were performed in a humidified chamber. Between incubations, specimens were washed three times in tris-buffered saline. All samples were processed in parallel. Omission of primary antibody resulted in completely negative signal. Hematoxylin solution according to Gill was used to counterstain the slides.

Table 1 Clinicopathological details of tumor specimens

\begin{tabular}{|c|c|c|c|c|c|c|}
\hline Patient Nr. & Grade & Location & Origin & Size (diameter in $\mathrm{cm}$ ) & Sex & Age \\
\hline 1 & 1 & upper extremity & peripheral & 5 & male & 68 \\
\hline 2 & $\|$ & costae & central & 6 & male & 53 \\
\hline 3 & $\|$ & pelvis & central & 11 & female & 38 \\
\hline 4 & $\|$ & upper extremity & central & 3 & male & 81 \\
\hline 5 & III & lower extremity & central & 7 & male & 45 \\
\hline 6 & III & lower extremity & Central & 5 & female & 78 \\
\hline 7 & III & pelvis & peripheral & 7 & male & 65 \\
\hline 8 & III & upper extremity & central & 4 & female & 52 \\
\hline 9 & III & upper extremity & unclassified & 8 & female & 23 \\
\hline 10 & III & costae & central & 6 & female & 78 \\
\hline 11 & III & costae & peripheral & 4 & male & 65 \\
\hline 12 & III & scapula & unclassified & 6 & male & 71 \\
\hline
\end{tabular}

Clinicopathological data of the 12 chondrosarcomas regarding grade, location, origin, size, patient sex and age. 
A Leica DMRB microscope (Leica, Bensheim, Germany) was used to analyse and photograph the specimens. All specimens were stained with rabbit polyclonal antibody AF886 (R\&D Systems, Wiesbaden, Germany) and were confirmed with rabbit polyclonal antibody 500.201 (Novus Biologicals, Littleton, $\mathrm{CO}$ ) and two mouse monoclonal antibodies (clone 60.11 and clone 32.1, Novus Biologicals). Details of all primary and secondary antibodies used are given in table 2 .

\section{Cell line and culture conditions}

For cell culture studies the human chondrosarcoma cell lines SW1353 (also known as HTB-94) and Hs 819.T (both obtained from American Type Culture Collection) were cultured in Dulbecco's Modified Eagle Medium (PAA, Cölbe, Germany), supplemented with $10 \%$ fetal calf serum, penicillin $(50 \mathrm{U} / \mathrm{ml})$ and streptomycin $(50 \mu \mathrm{g} / \mathrm{ml})$. Cells were incubated at $37^{\circ} \mathrm{C}$ at $5 \% \mathrm{CO}_{2}$ in humidified air.

\section{Survivin immunofluorescence}

Chondrosarcoma cells were grown on glass slides and fixed over 10 minutes in $3.7 \%$ Formalin/PBS at room temperature. Next, sections were cooked for 20 minutes in citrate buffer ( $\mathrm{pH} 6.0,10 \mathrm{mmol} / \mathrm{l})$. The sections were blocked with phosphatase-buffered saline and 5\% fatfree dried milk for 30 minutes at room temperature. After incubation overnight with primary antibody at $4^{\circ} \mathrm{C}$ and thorough washing with tris-buffered saline, tissues were incubated with red fluorescent dye-labelled antirabbit immunoglobulin (Invitrogen, Karlsruhe, Germany) at $37^{\circ} \mathrm{C}$ for 1 hour. Finally, the nuclei were stained with 4,6-diamidino-2-phenylindole $(6.5 \mathrm{~g} / \mathrm{ml}$; Invitrogen) for
10 minutes, and the stained sections were analysed and photographed with a fluorescence microscope (Zeiss, Jena, Germany).

\section{Protein extraction and immunoblot analysis}

Protein extraction of tissues and cells was performed as previously described [20]. In brief, cell pellets and tissues were homogenized into extraction buffer $(7 \mathrm{~mol} / \mathrm{L}$ urea, $10 \%$ glycerol, $10 \mathrm{mmol} / \mathrm{L}$ Tris- $\mathrm{HCl}, \mathrm{pH} 6.8,1 \%$ sodium dodecyl sulfate, $5 \mathrm{mmol} / \mathrm{L}$ dithiothreitol, 0.5 $\mathrm{mmol} / \mathrm{L}$ phenylmethyl sulfonyl fluoride with $1 \mathrm{mg} / \mathrm{L}$ aprotinin, pepstatin, and leupeptin) using a T8 UltraTurrax homogenizer (IKA, Staufen, Germany). After quantification, protein samples were run on $14 \%$ polyacrylamide gels and transferred to Immobilon $\mathrm{P}$ membranes (Millipore, Bedford, MA). Unspecific binding-sides were blocked with PBS and 5\% fat-free dried milk for 30 minutes at room temperature. Membranes were probed with either polyclonal antibody AF886 (1:1000, R\&D Systems) or monoclonal antibody NB500238 (clone 60.11, 1:500, Novus Biologicals) and horseradish peroxidase-conjugated secondary antibodies (DAKO). Signals were visualized by chemiluminescence (Pierce, Rockford, IL). Recombinant full-length human survivin served as positive control (R\&D Systems).

\section{Survivin knockdown by siRNA}

Knockdown of survivin was performed by the transfection of short interfering RNA (siRNA) as described in $[19,21,22]$. The transfection of human survivin mRNAspecific RNA oligonucleotides suppressed survivin expression effectively at a concentration of $100 \mathrm{nmol} / \mathrm{L}$ (suvivin 1). Knock down experiments were confirmed by

Table 2 Details of antibodies used

\begin{tabular}{|c|c|c|c|c|c|}
\hline Method & $\begin{array}{l}\text { Detected } \\
\text { protein }\end{array}$ & Primary antibody & $\begin{array}{l}\text { Concentration } \\
(\mu \mathrm{g} / \mathrm{ml})\end{array}$ & Secondary antibody & $\begin{array}{c}\text { Concentration } \\
(\mu \mathrm{g} / \mathrm{ml})\end{array}$ \\
\hline $\mathrm{IHC}$ & Survivin & pAB AF886 (R\&D Systems) & 5 & $\begin{array}{l}\text { Goat anti-rabbit immunoglobulin/biotinylated } \\
\text { (DAKO) }\end{array}$ & 4 \\
\hline $\mathrm{IHC}$ & Survivin & $\begin{array}{l}\text { mAB clone } 32.1 \text { (Novus } \\
\text { Biologicals) }\end{array}$ & 6 & $\begin{array}{l}\text { Swine anti-mouse immunoglobulin/biotinylated } \\
\text { (DAKO) }\end{array}$ & 4 \\
\hline $\mathrm{IHC}$ & Survivin & $\begin{array}{l}\text { pAB } 500.201 \text { (Novus } \\
\text { Biologicals) }\end{array}$ & 4 & $\begin{array}{l}\text { Goat anti-rabbit immunoglobulin/biotinylated } \\
\text { (DAKO) }\end{array}$ & 4 \\
\hline $\mathrm{IHC}$ & Survivin & $\begin{array}{l}\text { mAB clone } 60.11 \text { (Novus } \\
\text { Biologicals) }\end{array}$ & 7 & $\begin{array}{l}\text { Swine anti-mouse immunoglobulin/biotinylated } \\
\text { (DAKO) }\end{array}$ & 4 \\
\hline IF & Survivin & pAB AF886 (R\&D Systems) & 2 & $\begin{array}{l}\text { Red fluorescent dye-labeled anti-rabbit } \\
\text { immunoglobulin (Invitrogen) }\end{array}$ & 1 \\
\hline $\mathrm{IF}$ & Survivin & $\begin{array}{l}\text { mAB clone } 60.11 \text { (Novus } \\
\text { Biologicals) }\end{array}$ & 2 & $\begin{array}{l}\text { Red fluorescent dye-labeled anti-mouse } \\
\text { immunoglobulin (Invitrogen) }\end{array}$ & 1 \\
\hline IB & Survivin & pAB AF886 (R\&D Systems) & 1 & $\begin{array}{l}\text { Swine anti-rabbit immunoglobulins/HRP-conjugated } \\
\text { (DAKO) }\end{array}$ & 0,2 \\
\hline $\mathrm{IB}$ & Survivin & $\begin{array}{l}\text { mAB clone } 60.11 \text { (Novus } \\
\text { Biologicals) }\end{array}$ & 2 & $\begin{array}{l}\text { Swine anti-mouse immunoglobulin/HRP-conjugated } \\
\text { (DAKO) }\end{array}$ & 0,2 \\
\hline
\end{tabular}

Primary and secondary antibodies used for immunohistochemistry, immunofluorescence, and immunoblotting are listed, with inclusion of sources, purpose, and antibody concentrations. IB - immunoblot, IHC - immunohistochemistry, IF - immunofluorescence. 
the application of a second independent pair of siRNA (survivin 2) which resulted in similar reductions of survivin mRNA and protein levels. For negative controls, siRNA targeting green fluorescence protein (GFP) was transfected. 24 hours after knockdown cell cycle distribution and apoptosis were analysed. Sequencences of siRNAs used are given in Table 3.

\section{Overexpression of survivin}

Expression plasmid encoding wild type survivin was generously provided by R. Stauber [23]. One day before transfection, cells were plated at a density of $\sim 50 \%$ and expression plasmids were transfected into chondrosarcoma cells using a commercially available transfection reagent (FuGENE ${ }^{\circledR}$ HD, Roche Applied Science, Mannheim, Germany). Conditions according to the manufacturer's instructions. Transfection of pcDNA3 (Invitrogen) served as a negative control. The medium was removed and replaced with full growth medium 6 hours after transfection. The cells were further incubated at $37^{\circ} \mathrm{C}$ and $5 \% \mathrm{CO}_{2}$ in humidified air. Transfection efficacy was controlled by immunoblot.

\section{Cell Cycle Analysis}

Both adherent and detached chondrosarcoma cells were collected by trypsinization and washed with PBS for 5 minutes by centrifugation at $125 \times \mathrm{g}$. Cells were resuspended in a staining solution containing $1.5 \mu \mathrm{mol} / \mathrm{L}$ propidium iodide and $25 \mu \mathrm{g} / \mathrm{ml}$ RNase A and incubated for 30 minutes in $37^{\circ} \mathrm{C}$. The samples (10000 cells) were analyzed by fluorescence-activated cell sorting with a FACSCalibur (BD Biosciences, Heidelberg, Germany).

\section{Caspase 3/7 Activity Assay}

Apoptosis in chondrosarcoma cells in vitro was studied by measuring the activity of caspases 3 and 7 using a commercial kit (Caspase-Glo; Promega, Mannheim, Germany). Cells were seeded in 6 well dishes at $1.5 \times 10^{5}$ per $3.5 \mathrm{~cm}$ well, 24 hours before knockdown was

\section{Table 3 Details of siRNA used}

\begin{tabular}{ccc}
\hline Gene & Sense and antisense sequences & Reference \\
\hline Survivin 1 & 5'-CTTGGCCCAGTGTTTCTTCT-3' & {$[19,21]$} \\
& 5'-UGGCUCUUUCUCUGUCCAGTT-3' & \\
Survivin 2 & 5'-GCGCCUGCACCCCGGAGCG-3' & {$[22]$} \\
& 5'-CGCUCCGGGGUGCAGGCGC-3' & \\
GFP & 5'-GGUGUGCUGUUUGGAGGUCTT-3' & {$[20]$} \\
& 5'-GAACUCCAAACAGCACACCTT-3' & \\
\hline
\end{tabular}

RNA oligonucleotides with 3'-TT overhangs used for specific gene knockdown Target gene, sense and antisense sequences and references are listed. GFP green fluorescent protein. performed. For analysis, 24 hours after knock down cells were incubated for 90 minutes in a luciferase substrate mix. Finally supernatant was removed and cells were homogenized in lysate buffer. Buffer was transferred into a 96-well microplate and luminescence activity was measured in a luminometer (Berthold, Bad Wildbad, Germany). Apoptosis was induced by 24 hours exposure to doxorubicin $(5 \mu \mathrm{M})$. This concentration resembles the peak plasma level in oncologic patients receiving doxorubicin based treatment regimens [24].

\section{Measurement of cell viability by MTT}

The viability of chondrosarcoma cells was measured by methyl thiazolyl tetrazolium (MTT) assay. Cells were plated onto 96-well plates at a density of 5000 cells per well. 6 hours after transfection with specific siRNA or plasmid, the serum-free medium was replaced by complete medium. The transfection was repeated after 48 hours. MTT reagent $(5 \mathrm{mg} / \mathrm{ml})$ in $180 \mu \mathrm{l}$ medium was added at $0,24,48,72$ and 96 hours and incubated for 4 hours at $37^{\circ} \mathrm{C}$. Next, supernatant was removed and $150 \mu \mathrm{l}$ dimethyl sulphoxide (DMSO) was added to each well. After the plate was shaken on a rotary platform for $10 \mathrm{~min}$, extinction at wavelength $490 \mathrm{~nm}$ was measured.

\section{Measurement of cell proliferation}

Cell proliferation of chondrosarcoma cells (SW1353 and Hs819.T) was measured by analyzing BrdU incorporation into newly synthesized DNA using a commercially available ELISA chemiluminescence assay (Roche Molecular Biochemicals). Cells were plated out in 96-well microtiterplates at a density of 5000 cells per well and incubated for 24 hours prior the knock down of survivin was performed. 24 after the transfection of specific siRNA the cells were pulsed for BrdU incorporation over 4 hours. ELISA was performed according to the manufacturer's instructions. Chemiluminescence values (relative light units) were measured by an automated luminometer (Berthold, Bad Wildbad, Germany).

\section{RNA extraction and real-time PCR}

Survivin mRNA expression was assayed by performing real-time PCR as described in [19]. In short, RNA was extracted by column purification using the RNeasy micro kit (Qiagen, Hilden, Germany) and RNA transcribed into cDNA. Survivin mRNA expression was detected by a set of intron-spanning primer sequences for human survivin (survivin 1) and was verified by the application of an independent primer set (survivin 2). Control was human $\beta$-actin. For primer details see table 4 . All primers were applied at a concentration of $300 \mathrm{nmol} / \mathrm{L}$ and $55^{\circ} \mathrm{C}$ annealing temperature. A commercial $2 \times$ SYBR Green PCR Mix (Eurogentec, Seraing, Belgium) was used according to the manufacturer's instructions. PCR was 
Table 4 Details of primers used for RT-PCR

\begin{tabular}{ccc}
\hline Gene & Forward and reverse primer sequences & Reference \\
\hline Survivin (1) & 5'-AGTGAGGGAGGAAGAAGGCA-3' & {$[24]$} \\
& 5'-ATTCACTGTGGAAGGCTCTGC-3' & \\
Survivin (2) & 5'-CTTGGCCCAGTGTTCTTCT-3' & {$[20]$} \\
& 5'-CCTCCCAAAGTGCTGGTATT-3' & \\
B-Actin & 5'-AGTCCTGTGGCATCCACGAAA-3' & {$[20]$} \\
& 5'-GTCATACTCCTGCTTGCTGA-3' & \\
\hline
\end{tabular}

Primer sets applied for the detection of survivin and $\beta$-Actin mRNA.

performed with 50 cycles, taking $2 \mu \mathrm{l}$ of cDNA into the reaction with an end volume of $25 \mu \mathrm{l}$. Values for survivin were related to their controls using the $2^{-\Delta c t}$ calculation method.

\section{Statistics}

At least three replicates for each experimental condition were performed, and the presented results were representative of these replicates. All values are presented as means \pm SEM. Student's paired t-test was applied to reveal statistical significances. $P$ values less than 0.05 were considered significant. Statistical analyses were performed using SPSS Software for Windows (version 13.0; SPSS, Inc., Chicago, IL).

\section{Results}

\section{Survivin is expressed in human chondrosarcoma}

As a first step, we characterized survivin expression and subcellular distribution in human chondrosarcoma by immunohistochemistry. The staining of paraffinembedded samples revealed striking expression of survivin protein in all chondrosarcomas analyzed $(n=12)$ (Figure 1A and 1C). Higher magnification displays the strong, predominantly cytoplasmatic subcellular distribution of survivin protein (Figure $1 \mathrm{~B}$ and $1 \mathrm{D}$ ). In grade III chondrosarcoma $(n=8)$, approximately $30 \%$ of visible nuclei stained positive for survivin protein. Importantly, cells displaying mitotic structures and tumor giant cells displayed the strongest staining intensity (Figure 1E). To ascertain the specificity of the pattern of staining, we aimed to verify these findings with several independent antibodies. Altogether, we confirmed the result with two polyclonal (AF866 and pAB 500.201) and two monoclonal (clone 32.1 and clone 60.11) antibodies, where omission of primary antibody gave no signal (data not shown). To strengthen further the evidence of survivin expression in chondrosarcoma we aimed to verify protein expression with techniques other than immunohistochemistry. Hence, tissue lysates of 3 high-grade chondrosarcomas (Patient Nr. 5, 7, 10) showed specific signals for survivin protein by immunoblotting (Figure 1F). To ascertain the correct molecular weight of $16.8 \mathrm{kDa}$, in vitro-transcribed and -translated (IVTT) recombinant survivin protein was loaded. Lysates of adult human articular cartilage $(n=6)$ served as negative controls. Cartilage number 1 showed a faint band at approximately $28 \mathrm{kDa}$ and cartilage 2 revealed a very weak band at $16.8 \mathrm{kDa}$. The macro- and microscopically non-arthritic cartilage specimens were obtained from patients undergoing total knee arthroplasty because of mono- or bicompartmental osteoarthritis.

\section{Survivin is expressed in human chondrosarcoma cells in vitro and localizes to heterogenous subcellular compartments}

Having established that survivin is expressed in human chondrosarcoma, we next examined the survivin expression characteristics in human chondrosarcoma cell line SW1353. Survivin immunofluorescence of SW1353 cells cultured on glass slide revealed a predominantly cytoplasmic localization ( $\sim 65 \%$ of cells) of the protein, while approximately $30 \%$ of cells displayed mixed cytoplasmicnuclear staining (Figure 2A-C). A minor fraction of cells $(<5 \%)$ showed a predominantly nuclear staining, which may indicate imminent cell division (Figure 2D-F). In less than $1 \%$ of cells mitotic structures like spindle apparatus and midbody were seen (Figure 2G-I). Of note, the staining intensity in these cells was by far higher compared to the adjacent, interphasic cells. This finding is consistent with preceding reports describing the mitotic up-regulation of survivin mRNA and protein. Immunofluorescence studies of the human chondrosarcoma cell line Hs 819.T revealed a similar pattern of subcellular survivin protein distribution (data not shown).

\section{Knock-down of Survivin in chondrosarcoma cells results in reduced rates of proliferation and a failure to exit mitosis}

After studying the subcellular localization of survivin protein in chondrosarcoma cell in vitro, the functional role of survivin was analysed by using RNA interference. Transfection of survivin specific siRNA resulted in a significant knockdown of survivin protein and mRNA in SW1353 and Hs819.T cells (Figure 3A and 3B). The influence of survivin on cell viability in SW1353 (Figure 4A left) and Hs819.T (Figure 4A right) was analysed by colorimetric measurement of methyl thiazolyl tetrazolium uptake. Knock-down was performed at the beginning of the experiment ( 0 hours) and repeated on day 2 (48 hours). The MTT-assay revealed a significant lower amount of viable cells 48 hours after the transfection of survivin-specific siRNA (Extinction 0.51, SEM $+/-0.03)$ in SW 1353 compared to the no siRNA control (Extinction 0.64 SEM+/- 0.04). At 72 and 96 hours the 


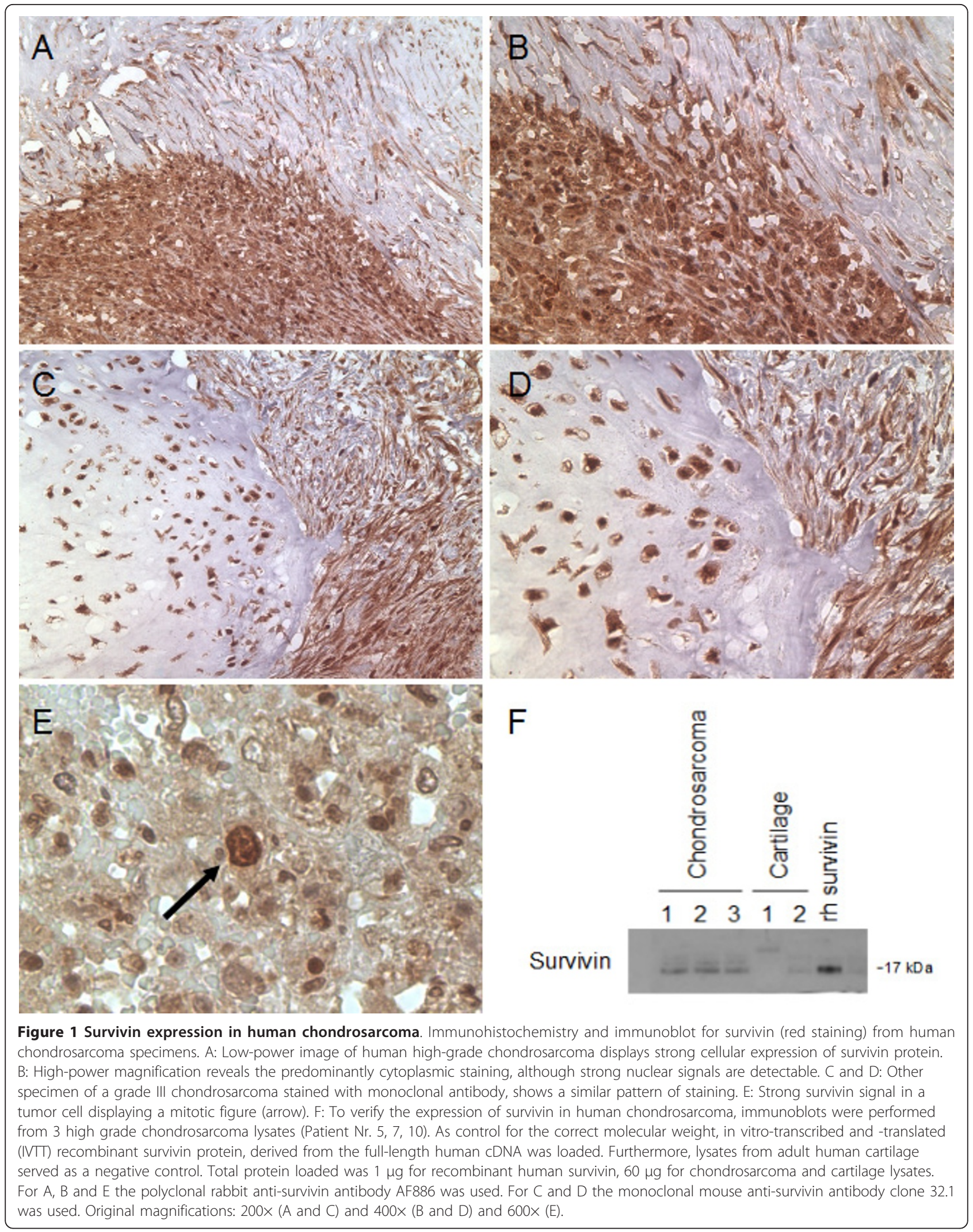



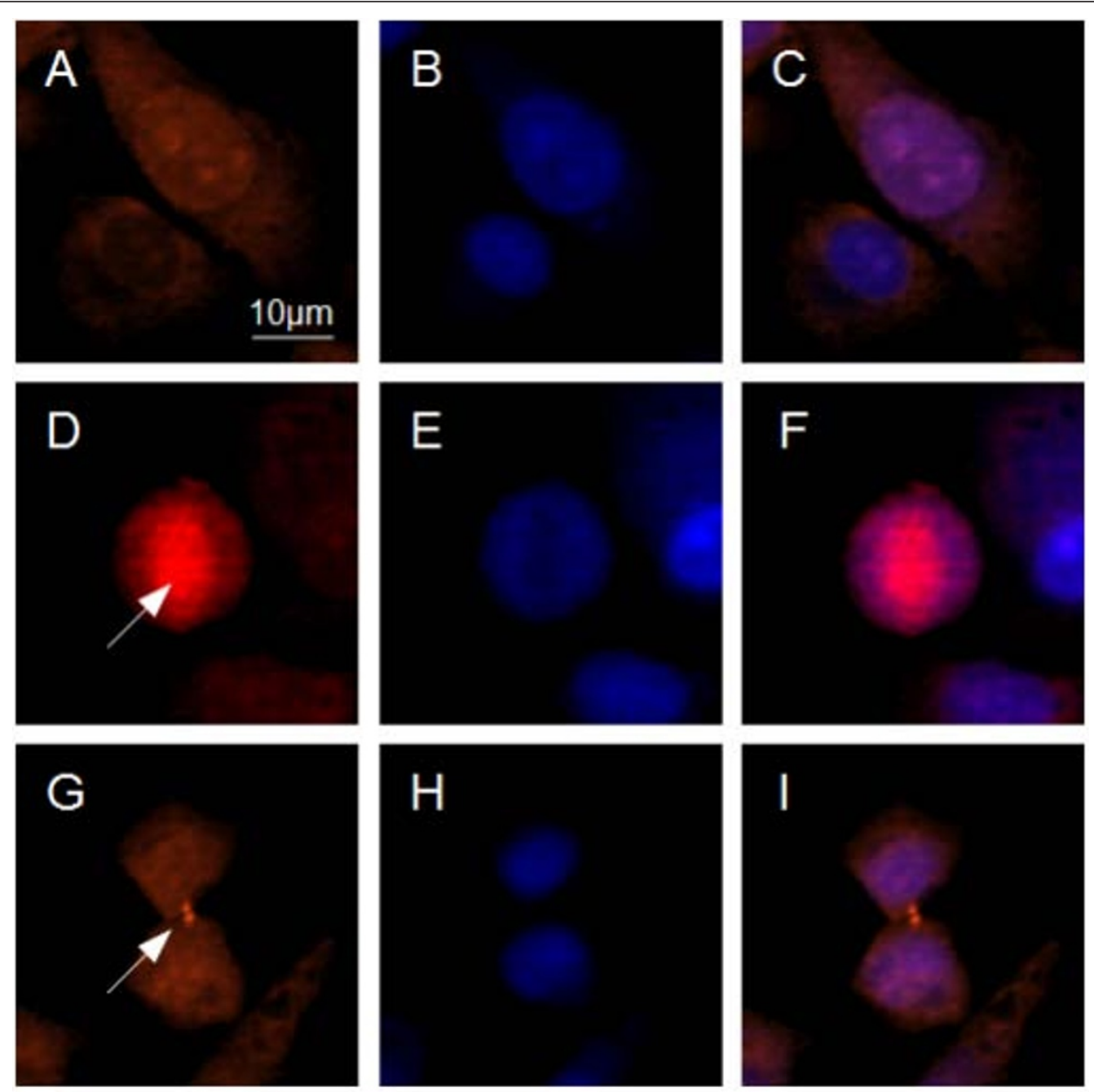

Figure 2 Survivin subcellular localization in human chondrosarcoma cells in vitro. Immunofluorescence localization of survivin using chondrosarcoma cells (SW1353) cultured on glass slides (A,D,G) and 4,6-diamidino-2-phenylindole-staining (DAPI) of the identical positions (B,E, H). Overlay of both stainings (C,F,I). A-C: The top row clearly shows the heterogeneous subcellular distribution from predominant cytoplasmic (lower cell) in the majority of the cell population to mixed cytoplasmic-nuclear in a smaller fraction of cells (upper cell). D-F: In a premitotic cell, survivin localizes to the mitotic spindle apparatus (arrow). Of note, here survivin signal appears stronger compared to the surrounding nonmitotic cells. G-I: In late telophase the mid-body (arrow) stains positive for survivin protein. Original magnifications: 400× (A-l)

reduction of detected viable cells after survivin knockdown was even more pronounced. Transfection of green fluorescent protein (GFP) specific siRNA served as an additional control and lead to no significant alterations of the amount of viable cells (data not shown). Analyzing the effects of survivin knock-down in $\mathrm{Hs}$ 819.T revealed a similar tendency towards reduction of measured cell viability (Figure 4A right). To study survivin's influence on cell proliferation in SW 1353 (Figure 3B left) and Hs819.T (Figure 4B right), BrdU incorporation was measured 24 hours after the knock down of survivin. In both cell lines the transfection of survivin specific siRNA led to significantly $(\mathrm{p}<0.05)$ reduced rates of proliferative activity after 24 hours.

Cell cycle regulation and involvement in mitotic spindle organization represent well characterized functions of survivin in cancer cells, therefore 24 hours after siRNA transfection in SW1353 cell cultures, cell cycle distribution was analyzed by propidium iodide staining and fluorescence-activated cell sorting (Figure 5). Suppression of survivin resulted in a 2.1 fold increase $(\mathrm{SEM}+/-0.3)$ of the fraction of cells within $G_{2} / M$ phase of the cell cycle (Figure 5C). This failure to exit mitosis was previously shown in other tumor cells and underlines survivin's important role in cell division. 


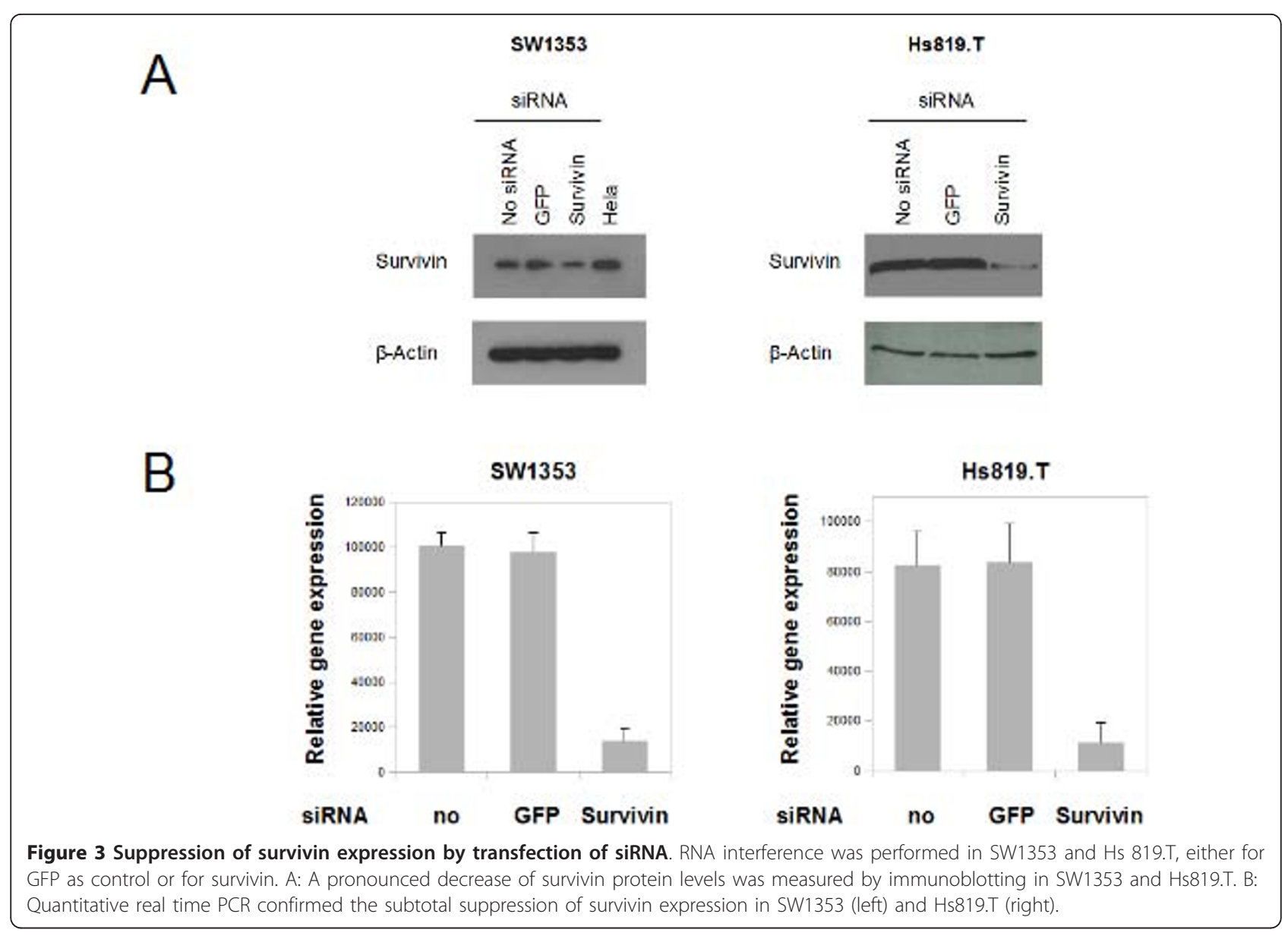

Knockdown of survivin sensitizes chondrosarcoma cells to apoptotic stimuli

In addition to cell cycle regulation and proliferation, we assayed for influences of survivin on apoptosis by caspase $3 / 7$ activity (Figure $6 \mathrm{~A}$ and $6 \mathrm{C}$ ) and propidium iodide staining and fluorescence-activated cell sorting (Figure 6B and 6D). Apoptotic activity was studied 24 hours after survivin knock-down in SW1353 and Hs819.T. Interfering with survivin's function led to an 1.9 fold increase of caspase 3/7 activity and increased the fraction of apoptotic SW 1353 cells 1.8 fold. Next, we tested whether cellular stresses in combination with survivin knockdown revealed a difference. Exposure to 5 $\mu \mathrm{M}$ doxorubicin increased the cellular fraction of apoptotic SW 1353 cells approximately threefold (Figure 6A, right) and caspase $3 / 7$ activity by almost 3.8 fold (Figure $6 \mathrm{~B}$, right). Following survivin specific RNA interference in SW 1353 cells doxorubicin exposure $(5 \mu \mathrm{M})$ resulted in an 8.3 fold increase of the apoptotic fraction and 12.8 fold increase of caspase 3/7 activity. Next, effects of survivin knock down on apoptosis were analyzed in a second cell line (Hs819.T). While isolated transfection of survivin specific siRNA led to no significant changes in caspase 3/7 activity (Figure 6C, left) or apoptotic fraction (Figure 5D, left), after Doxorubicin exposure the knock down significantly increased both apoptotic markers (Figure 6C and 6D, right).

Overexpression of survivin protects chondrosarcoma cells against doxorubicin induced apoptosis, but shows no effect on proliferation

Having established that down regulation of survivin gene expression resulted in inhibition of proliferation and increased rates of apoptosis, we next examined the effects of survivin overexpression in SW1353 cells. Overexpression of survivin resulted in a marked upregulation of detectable survivin protein after 24 and 48 hours. While, transfection of empty plasmid (pcDNA3) showed no changes in survivin protein levels (Figure 7A). First, proliferation was analysed by employing the MTT -assay (Figure 7B). Over 96 hours, no significant influences on proliferation were seen at any point of time. Next, we studied the effects of high levels of survivin on apoptosis by caspase $3 / 7$ activity (Figure $7 \mathrm{C}$ ) and propidium iodide staining and fluorescence-activated cell sorting (Figure 7D). Apoptotic activity was studied 24 hours after 


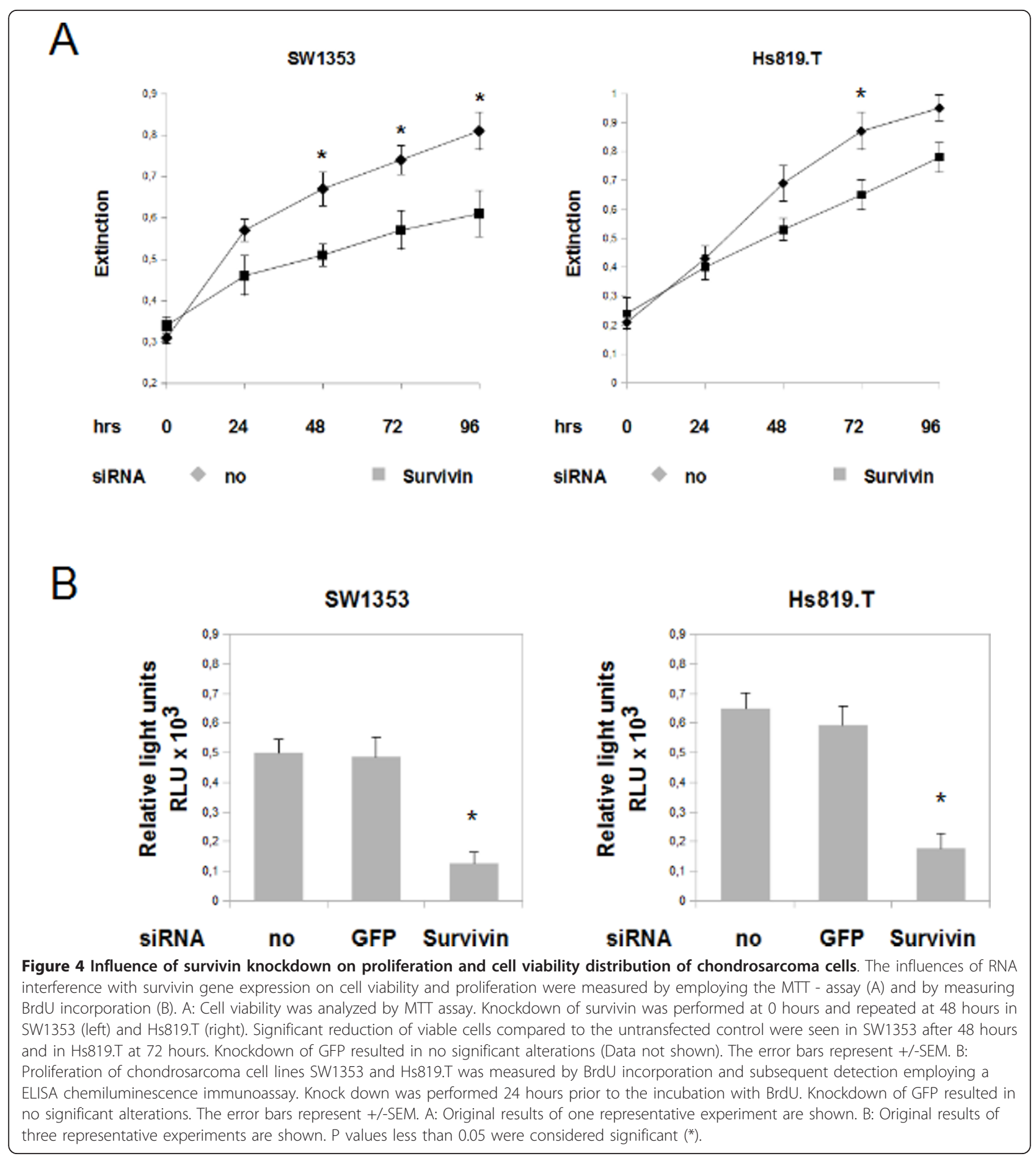

transfection with survivin or pcDNA3. Upregulation of survivin led to no significant changes in the spontaneous rate of apoptosis as shown by analysing apoptotic markers (Figure 7C and 7D, left). However, transfection of survivin under cytotoxic conditions ( $5 \mu \mathrm{M}$ doxorubicin) reduced both, apoptotic fraction (1.6 fold, Figure 7C, right) and caspase activity ( 2.2 fold, Figure $7 \mathrm{D}$, right).

\section{Discussion}

Previous studies have shown that survivin, the smallest member of the IAP protein family, has a bifunctional role in cellular division and survival decisions. It is highly expressed at mitosis and is a critical factor for completion of mitotic cell division $[15,16]$. Survivin acts as a potent inhibitor of apoptotic and non-apoptotic cell death, and 


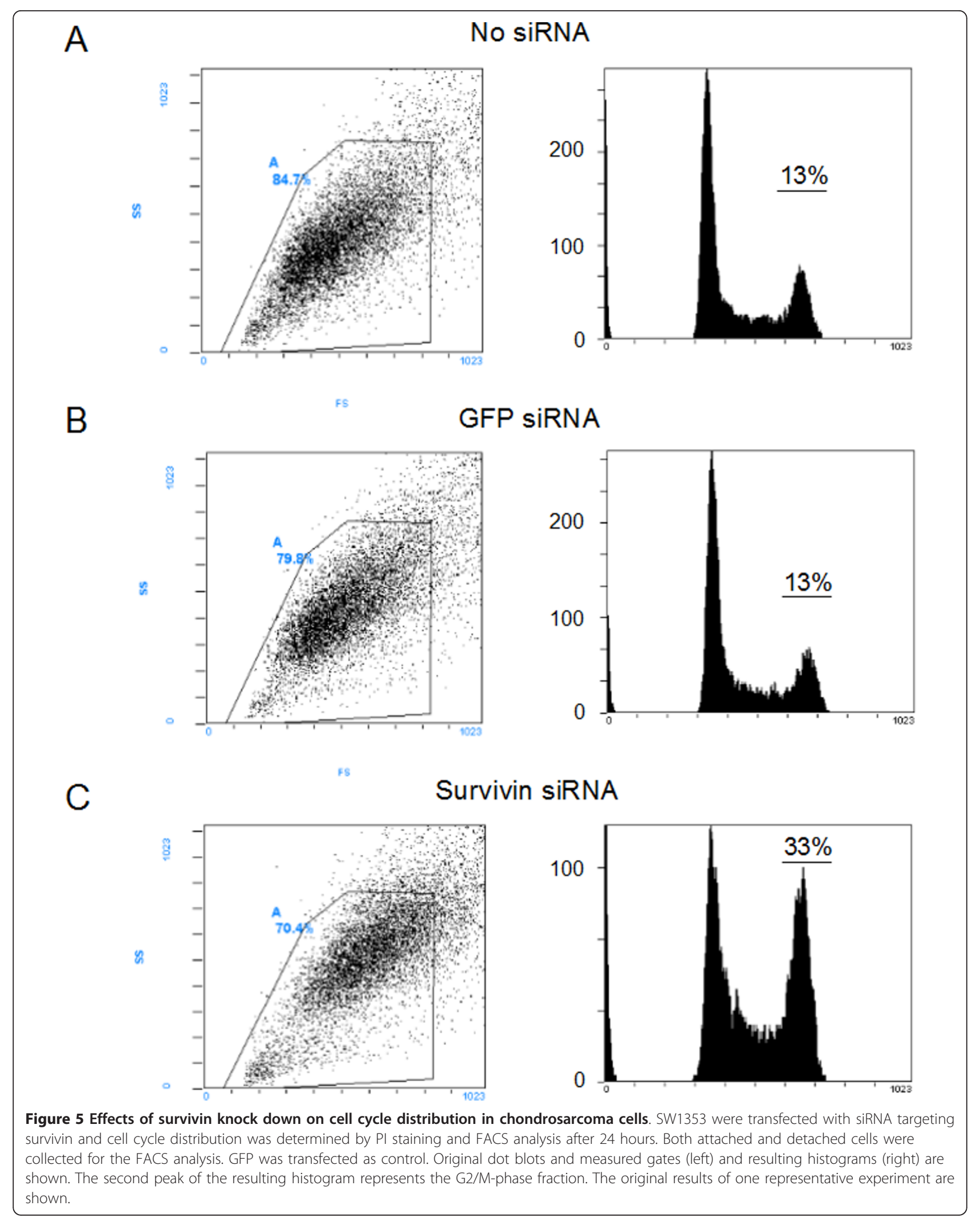


A

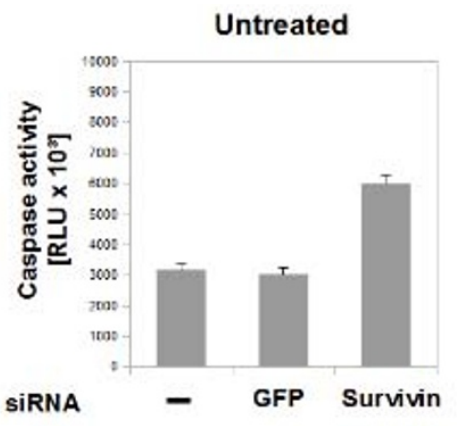

B

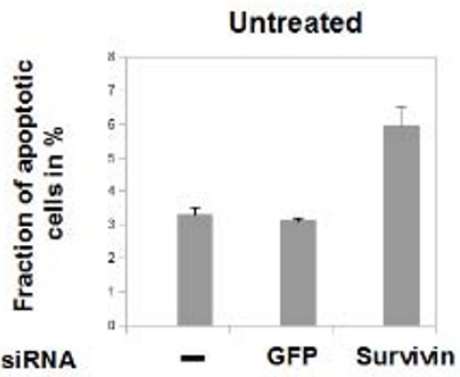

Doxorubicin $5 \mu \mathrm{M}$

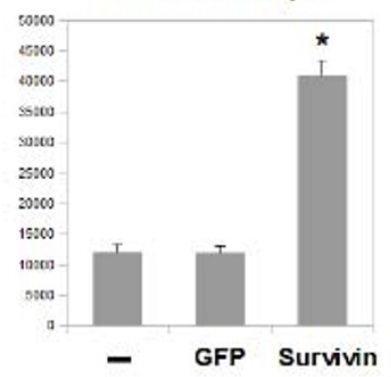

Doxorubicin $5 \mu \mathrm{M}$

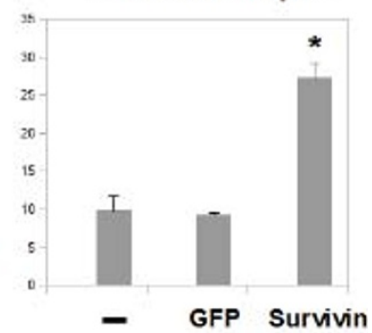

C
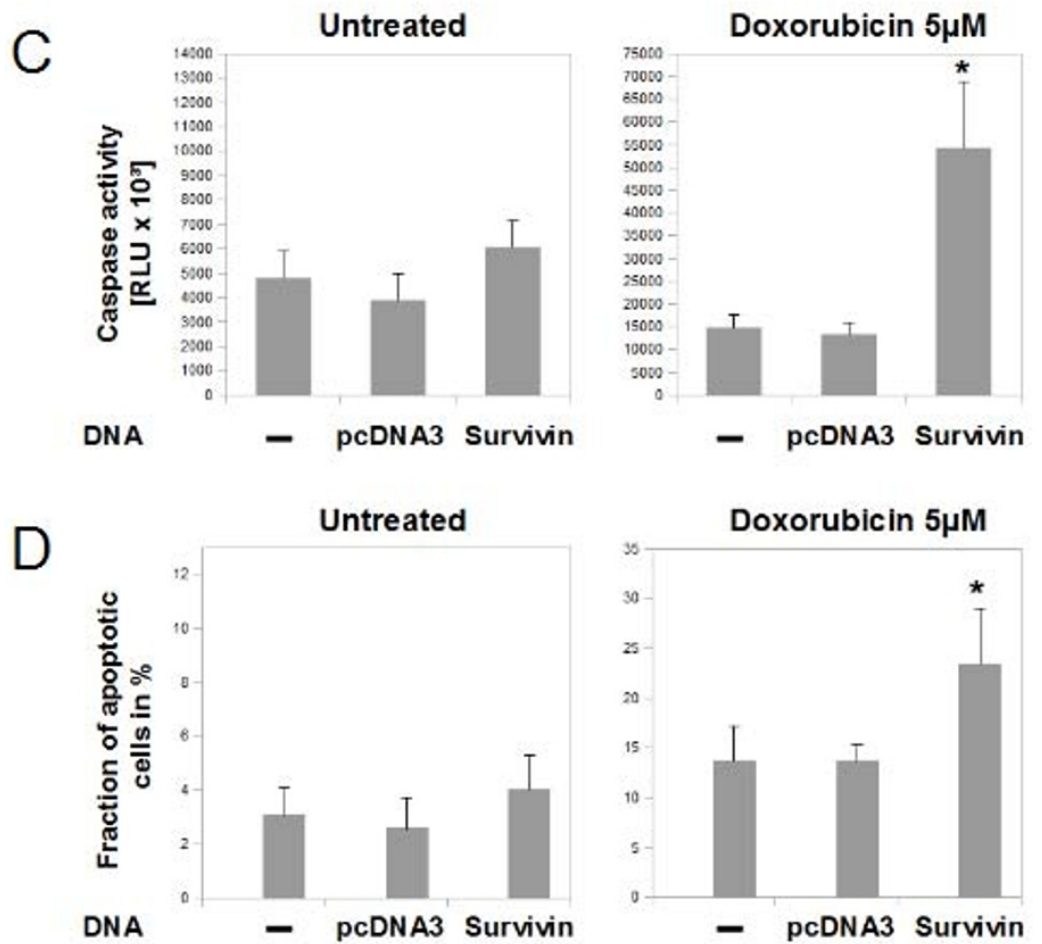

Figure 6 Influence of survivin knockdown on apoptotic rate of chondrosarcoma cells. Influences of RNA interference against survivin on programmed cell death of SW1353 (A and B) and Hs819.T (C and D) were measured by caspase 3/7 activity (A and C) and by analysing the sub$G_{0 / 1}$-phase fraction by using the fluorescence-activated cell sorting-propidium iodide staining method (B and D). Survivin knockdown resulted in moderate elevations of the indicators of apoptotic activity in SW 1353 (A and B, left) but not in Hs819.T (C and D). Transfection of GFP had no significant effects on apoptosis. Pronounced elevations of apoptotic markers were seen when the cells were stressed with doxorubicin $5 \mu \mathrm{M}$ over 24 hours (A - D, right). The cytotoxic treatment resulted in a substantial increase of caspase 3/7 activity and fraction of apoptotic cells. Suppression of survivin sensitized the cells to doxorubicin treatment and further increased the apoptotic activity significantly in both cell lines. Again, transfection of GFP siRNA was used as a control. The error bars represent +/-SEM. P values less than 0.05 were considered significant $(*)$. The original results of one representative experiment are shown. 

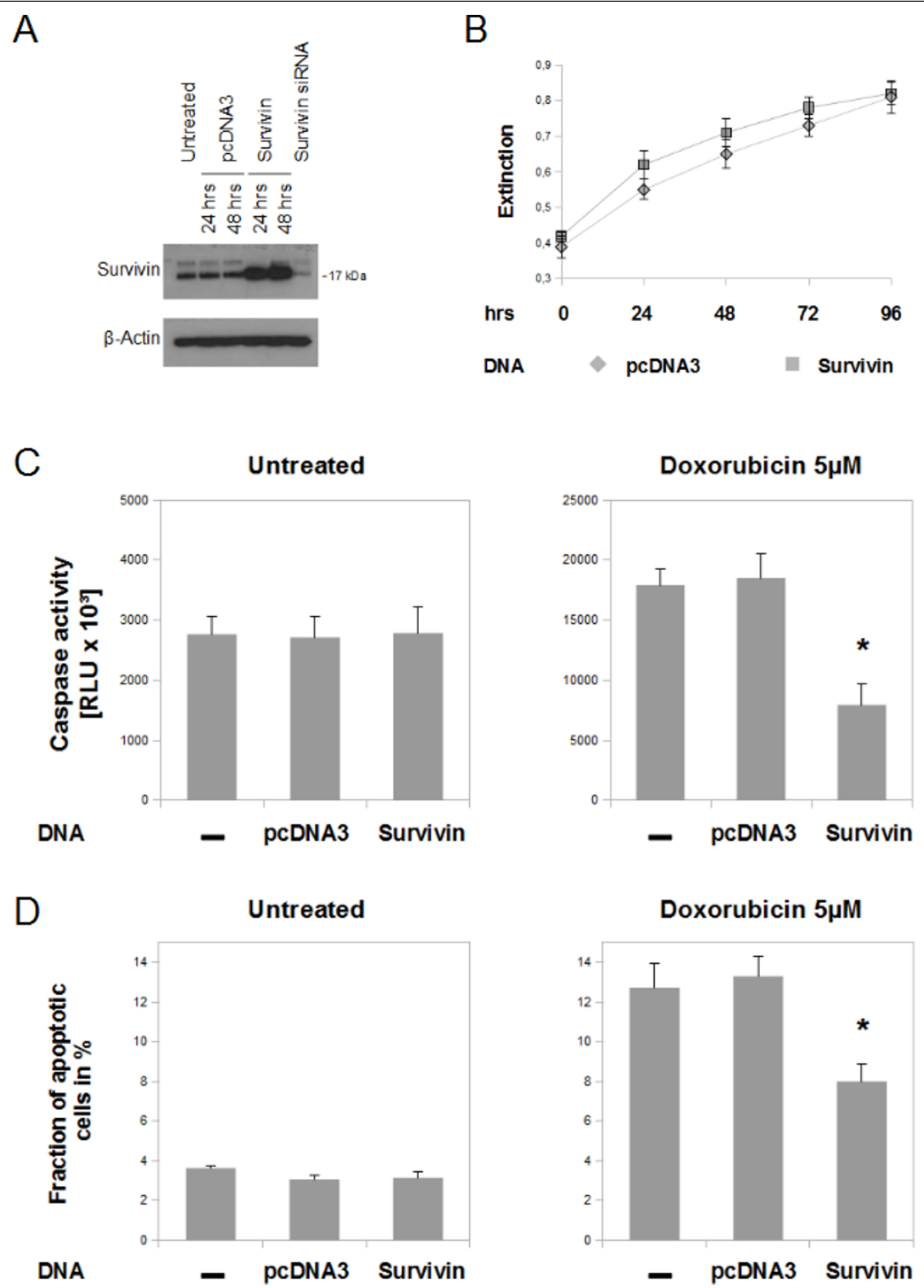

Figure 7 Influence of survivin overexpression on proliferation and apoptosis of chondrosarcoma cells in vitro. A: Overexpression of human full length survivin by transfection of plasmid DNA led to a significant increase of protein level, as measured by immunoblot. Empty vector pcDNA3 was transfected as control. B: MTT - analysis over 5 days after transfection showed no influences on the proliferative activity of SW1353. C and D: Overexpression of survivin resulted in no alterations of spontaneous apoptotic rate as measured by caspase 3/7 activity (C) and by analysing the sub- $G_{0 / 1}$-phase fraction by using the fluorescence-activated cell sorting-propidium iodide staining method (D). When SW1353 cells were exposed for 24 hours to doxorubicin ( $5 \mu \mathrm{M})$ (right) the apoptotic fraction and caspase activity of not transfected and pcDNA3 transfected cells increased markedly. Transfection of survivin resulted in significantly reduced rates of apoptosis after cytotoxic treatment. The error bars represent +/-SEM. P values less than 0.05 were considered significant $\left(^{*}\right)$. The original results of one representative experiment are shown. 
protects cells as a stress response factor against unfavourable environments. From a clinical point of view, the most interesting feature of survivin is the widely accepted concept of an "oncofetal" pattern of expression. While undetectable in most adult differentiated tissues, survivin is ubiquitously expressed during embryonal developement and highly re-expressed in cancer. In malignant tumors, survivin antagonizes programmed cell death, favours tumour-associated neovascularization, promotes cell proliferation and preserves cell viability [11]. Disregarding the yet undefined molecular mechanisms, a large body of evidence has demonstrated that survivin has indeed a strong potential of antagonizing drug and radiation induced apoptosis $[25,26]$. In the current study, we report high expression of survivin in human chondrosarcoma. Furthermore, in vitro experiments indicate a potential role in the tumor's pronounced resistance to chemotherapy. Our data shows homogeneous expression of survivin in all analysed human chondrosarcomas (Figure 1A-D), while in adult cartilage no or only low levels of survivin protein were detectable (Figure $1 \mathrm{~F}$ ). Immunohistochemistry revealed a predominantly cytoplasmic pattern of staining in chondrosarcoma. Immunofluorescence of cultured chondrosarcoma cells confirmed the cytoplasmic subcellular localization of survivin protein (Figure 2), indicating survivin's involvement in extranuclear (i.e. proliferation independent) functions. Of note, recent publications on survivin emphasize the prognostic relevance of subcellular distribution of survivin gene expression. While the prognostic value of nuclear survivin expression in cancer remains unclear, high levels of cytoplasmic survivin protein seem to correlate with resistance to drug/radiation therapy and poor patient outcome $[27,28]$. The unfavourable prognosis related to cytoplasmic survivin might be associated with its reported extranuclear function (e.g. counteracting apoptosis), whereas nuclear survivin could rather promote cell proliferation [29]. In this context it is of particular interest that effects of strongly active proapoptotic substances as doxorubicin are significantly reduced by survivin overexpression in SW1353 (Figure 7). Accordingly, downregulation of survivin resulted in increased rates of spontaneous and drug induced apoptosis (Figure 6). It is therefore tempting to speculate that survivin represents a key molecule in maintaining constitutive antiapoptotic activity in chondrosarcoma. In this context, it has been shown, that an upregulation of survivin protein did not increase cell proliferation or changed cell cycle distribution, while suppression of survivin resulted in a failure to exit mitosis, the previously described $\mathrm{G}_{2} / \mathrm{M}$-arrest [21].

\section{Conclusions}

In summary, we demonstrate that the antiapoptotic protein survivin is highly expressed in human high grade chondrosarcoma. Functional analyses in chondrosarcoma cells in vitro indicate that survivin exerts the classic functions of cell cycle regulation and survival control in human chondrosarcoma. Moreover, our findings indicate that survivin might be a potent promoter of resistance to chemotherapeutic agents in chondrosarcoma. Still, the role of survivin in oncogenesis and the relevance of its predominantly cytoplasmic distribution in human chondrosarcoma remain elusive.

Learning more about survivin's role in chondrosarcoma and evaluating the effects of survivin-antagonizing therapeutic strategies will be an important task for future studies.

\section{Abbreviations}

IAP: inhibitor of apoptosis protein; BIR: baculovirus inhibitor of apoptosis repeat; MTT: methyl thiazolyl tetrazolium; siRNA: small interfering RNA.

\section{Acknowledgements}

We thank Mrs. Luise Rauch and Mrs. Anja Sabo for excellent technical assistance, Dr. S. Capellino for kindly helping with the fluorescence microscope, and Dr. R. Stauber for the gift of the human cDNA for survivin. The study was supported by the Regensburger Forschungsförderung in der Medizin (ReForM)

\section{Author details}

'Department of Orthopedic Surgery, Regensburg University Medical Center, Asklepios Klinikum Bad Abbach, Bad Abbach, Germany. 'Department of Pathology, University Hospital of Erlangen, University of Erlangen-Nuremberg, Erlangen, Germany. ${ }^{3}$ Department of Internal Medicine, Imperial College London, Hammersmith Campus, London, UK. ${ }^{4}$ Department of Orthopedics, RWTH University Hospital, Aachen, Germany.

\section{Authors' contributions}

PL and JS designed research. PL, VC and TR performed experimental study. PL and JS performed statistical analysis. JG and MT participated in data interpretation. PL, JS and JG drafted the manuscript. All authors read and approved the final manuscript.

\section{Competing interests}

The authors declare that they have no competing interests.

Received: 7 November 2010 Accepted: 2 April 2011

Published: 2 April 2011

\section{References}

1. World Health Organization: Pathology and Genetics. Tumours of Soft Tissue and Bone. In World Health Organization Classification of Tumours. Cartilage tumours. Edited by: Fletcher CD, Unni KK, Mertens F. Lyon, IARC Press; 2002:234-257.

2. Damron TA, Ward WG, Stewart A: Osteosarcoma, chondrosarcoma, and Ewing's sarcoma: National Cancer Data Base Report. Clin Orthop Relat Res 2007, 459:40-7.

3. Eriksson Al, Schiller A, Mankin HJ: The management of chondrosarcoma of bone. Clin Orthop 1980, 153:44-66.

4. Dorfmann HD, Czerniak B: Bone Tumors. Mosby, St. Louis; 1998.

5. Gelderblom H, Hogendoorn PC, Dijkstra SD, van Rijswijk CS, Krol AD, Taminiau AH, Bovée JV: The clinical approach towards chondrosarcoma. Oncologist 2008, 13:320-9.

6. Evans HL, Ayala AG, Romsdahl MM: Prognostic factors in chondrosarcoma of bone. A clinicopathologic analysis with emphasis on histologic grading. Cancer 1977, 40:818-31.

7. Lee FY, Mankin HJ, Fondren G, Gebhardt MC, Springfield DS, Rosenberg AE, Jennings LC: Chondrosarcoma of bone: an assessment of outcome. J Bone Joint Surg Am 1999, 81:326-38. 
8. Schrage YM, Briaire-de Bruijn $H_{\text {, }}$ de Miranda NF, van Oosterwijk J, Taminiau AH, van Wezel T, Hogendoorn PC, Bovée JV: Kinome Profiling of Chondrosarcoma Reveals Src-Pathway Activity and Dasatinib as Option for Treatment. Cancer Res 2009, 69:6216-6222.

9. Bovée JV, Cleton-Jansen AM, Taminiau AH, Hogendoorn PC: Emerging pathways in the development of chondrosarcoma of bone and implications for targeted treatment. Lancet Oncol 2005, 6:599-607.

10. Kim DW, Kim KO, Shin MJ, Ha JH, Seo SW, Yang J, Lee FY: siRNA-based targeting of antiapoptotic genes can reverse chemoresistance in $\mathrm{P}$ glycoprotein expressing chondrosarcoma cells. Mol Cancer 2009, 15(8):28.

11. Altieri DC: The case for survivin as a regulator of microtubule dynamics and cell-death decisions. Curr Opin Cell Biol 2006, 18:609-615.

12. Ambrosini G, Adida C, Altieri DC: A novel anti-apoptosis gene, survivin, expressed in cancer and lymphoma. Nat Med 1997, 3:917-921.

13. Verdecia MA, Huang $H$, Dutil E, Kaiser DA, Hunter T, Noel JP: Structure of the human anti-apoptotic protein survivin reveals a dimeric arrangement. Nat Struct Biol 2000, 7:602-608.

14. Altieri DC: Survivin, cancer networks and pathway-directed drug discovery. Nat Rev Cancer 2008, 8:61-70.

15. Skoufias DA, Mollinari C, Lacroix FB, Margolis RL: Human survivin is a kinetochore-associated passenger protein. J Cell Biol 2000, 151:1575-1582.

16. Kobayashi K, Hatano M, Otaki M, Ogasawara T, Tokuhisa T: Expression of a murine homologue of the inhibitor of apoptosis protein is related to cell proliferation. Proc Natl Acad Sci USA 1999, 96:1457-1462.

17. Fukuda S, Pelus LM: Survivin, a cancer target with an emerging role in normal adult tissues. Mol Cancer Ther 2006, 5:1087-98.

18. Machado I, Giner F, Mayordomo E, Carda C, Navarro S, Llombart-Bosch A: Tissue microarrays analysis in chondrosarcomas: light microscopy, immunohistochemistry and xenograft study. Diagn Pathol 2008, 15:25.

19. Lechler P, Wu X, Bernhardt W, Campean V, Gastiger S, Hackenbeck T, Klanke B, Weidemann A, Warnecke C, Amann K, Engehausen D, Willam C, Eckardt KU, Rödel F, Wiesener MS: The tumor gene survivin is highly expressed in adult renal tubular cells: implications for a pathophysiological role in the kidney. Am J Pathol 2007, 171:1483-98.

20. Wiesener MS, Jurgensen JS, Rosenberger C, Scholze CK, Horstrup JH, Warnecke C, Mandriota S, Bechmann I, Frei UA, Pugh CW, Ratcliffe PJ, Bachmann S, Maxwell PH, Eckardt KU: Widespread hypoxia-inducible expression of HIF-2 in distinct cell populations of different organs. FASEB J 2003, 17:271-273

21. Rödel F, Hoffmann J, Distel L, Herrmann M, Noisternig T, Papadopoulos T, Sauer R, Rödel C: Survivin as a radioresistance factor, and prognostic and therapeutic target for radiotherapy in rectal cancer. Cancer Res 2005, 65:4881-7.

22. Ling $X$, Bernacki RJ, Brattain MG, Li F: Induction of survivin expression by taxol (paclitaxel) is an early event, which is independent of taxolmediated G2/M arrest. J Biol Chem 2004, 27915196-203.

23. Knauer SK, Bier C, Habtemichael N, Stauber RH: The Survivin-Crm1 interaction is essential for chromosomal passenger complex localization and function. EMBO Rep 2006, 12:1259-65.

24. Speth PA, Linssen PC, Boezeman JB, Wessels HM, Haanen C: Cellular and plasma adriamycin concentrations in long-term infusion therapy of leukemia patients. Cancer Chemother Pharmacol 1987, 20:305-310.

25. Olie RA, Simões-Wüst AP, Baumann B, Leech SH, Fabbro D, Stahel RA, Zangemeister-Wittke U: A novel antisense oligonucleotide targeting survivin expression induces apoptosis and sensitizes lung cancer cells to chemotherapy. Cancer Res 2000, 1:2805-9.

26. Ryan BM, O'Donovan N, Duffy MJ: Survivin: a new target for anti-cancer therapy. Cancer Treat Rev 2009, 35:553-62.

27. Taubert H, Heidenreich C, Holzhausen H, Schulz A, Bache M, Kappler M, Eckert AW, Würl P, Melcher I, Hauptmann K, Hauptmann S, Schaser K: Expression of survivin detected by immunohistochemistry in the cytoplasm and in the nucleus is associated with prognosis of leiomyosarcoma and synovial sarcoma patients. BMC Cancer 2010, 10:65.

28. Engels K, Knauer SK, Metzler D, Simf C, Struschka O, Bier C, Mann W, Kovács AF, Stauber RH: Dynamic intracellular survivin in oral squamous cell carcinoma: underlying molecular mechanism and potential as an early prognostic marker. J Pathol 2007, 211:532-540.

29. Li F, Yang J, Ramnath N, Javle MM, Tan D: Nuclear or cytoplasmic expression of survivin: what is the significance? Int J Cancer 2005, 114:509-12.

\section{Pre-publication history}

The pre-publication history for this paper can be accessed here: http://www.biomedcentral.com/1471-2407/11/120/prepub

doi:10.1186/1471-2407-11-120

Cite this article as: Lechler et al:: The antiapoptotic gene survivin is highly expressed in human chondrosarcoma and promotes drug resistance in chondrosarcoma cells in vitro. BMC Cancer 2011 11:120.

\section{Submit your next manuscript to BioMed Central and take full advantage of:}

- Convenient online submission

- Thorough peer review

- No space constraints or color figure charges

- Immediate publication on acceptance

- Inclusion in PubMed, CAS, Scopus and Google Scholar

- Research which is freely available for redistribution

Submit your manuscript at www.biomedcentral.com/submit
Biomed Central 